\title{
Allogeneic Multivirus-specific Cytotoxic T Lymphocytes
}

National Cancer Institute

\section{Source}

National Cancer Institute. Allogeneic Multivirus-specific Cytotoxic T Lymphocytes. NCI

Thesaurus. Code C115107.

A population of closely human leukocyte antigen (HLA)-matched, donor-derived cytotoxic T lymphocytes (CT Ls) that are specifically reactive towards five viruses, Epstein-Barr virus (EBV), cytomegalovirus (CMV), adenovirus (AdV), human herpesvirus 6 (HHV6), and human polyomavirus type I (BKV), with potential antiviral activity. Infusion of the multivirus-specific CT Ls into allogeneic hematopoietic stem cell transplant (HSCT) recipients provides virus-specific cellular immunity and causes specific anti-viral effects against active viral infections. The administered CT Ls also prevent EBV, CMV, AdV, HHV6, and BKV reactivation and infection as well as inhibiting viral-associated diseases in immunocompromised patients. The allogeneic multivirus-specific CT Ls may also provide cellular immunity towards the human polyomavirus type II (JC virus; JCV), which is highly homologous to BKV. 